\title{
Prácticas productivas, lógicas culturales Y TRANSFORMACIONES EN LA ALTA MONTAÑA. Cundinamarca, IgOo-I980
}

\author{
Ingreet Juliet Cano Castellanos \\ Grupo de Restauración Ecológica. Universidad Nacional de Colombia \\ julietccano@yahoo.com
}

Resumen

[ L ARTíCULO RECONSTRUYE LA TRANSFORMACIÓN DE LOS PAISAJES EN LA VEREDA DE [ Quebrada Honda, municipio de Cogua (departamento de Cundinamarca), a lo largo del siglo veinte. Analiza, sobre todo, las lógicas culturales que subyacen a las prácticas productivas y dan sentido a la apropiación de los recursos, el manejo de los ecosistemas y las estrategias campesinas frente a la modernización agrícola. Además, contextualiza los procesos económicos y políticos que enmarcaron las dinámicas en la vereda e imprimieron un ritmo a la transformación de los paisajes. Con base en la reconstrucción lograda, discute algunos aspectos del escenario socioambiental actual, reflexionando sobre la capacidad de adaptación de las familias campesinas, la importancia de valorar su experiencia con los ecosistemas de alta montaña y las razones de su continuidad en el campo. PALABRAS CLAVE: prácticas productivas, lógicas culturales, paisaje, alta montaña, Cogua-Cundinamarca.

\begin{abstract}
THE PRESENT ARTICLE RECONSTRUCTS LANDSCAPE TRANSFORMATION IN THE VILLAGE of Quebrada Honda, Cogua-Cundinamarca, throughout the 20th Century. It analyses the cultural influences that underlay productive practices in the region and gives sense to resources appropriation, ecosystems management and the local community's strategies as opposed to agricultural modernization. In addition, it contextualizes the economic and political processes that frame the local dynamics giving rise to the landscapes transformation. Based on the achieved reconstruction, this article discusses some of the socio-environmental aspects of the current scenery, reflecting on the capacity of adaptation of local families, the importance of valuing their experiences within high mountain ecosystems and the reasons for their continued practice in these rural areas.
\end{abstract}

KEY wORDs: Productive practices, cultural influences, landscape, high mountain ecosystems, Cogua-Cundinamarca.

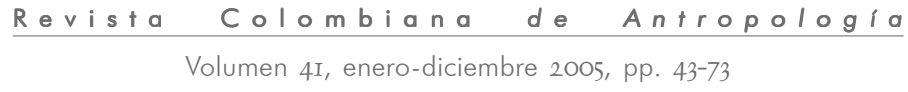




\section{INTRODUCCIÓN}

A

MEDIADOS DEL SIGLO VEINTE, LA SOCIEDAD RURAL DE LA VEREDA DE Quebrada Honda, en el municipio de Cogua -departamento de Cundinamarca- (véase el mapa), como otras sociedades rurales de Colombia, fue partícipe de la modernización de la agricultura impulsada por el estado. Tecnificación de la agricultura, uso intensivo de los suelos, ampliación de la frontera agrícola y aumento en la producción con fines comercializables se planteaban como factores fundamentales en la integración del campo a la economía nacional (González, 200I). Durante este proceso, los habitantes de la vereda se articularon al modelo de crecimiento económico, concentrándose en la obtención de beneficios monetarios procedentes de la manutención del ganado lechero y del monocultivo de la papa.

En la actualidad, los(as) habitantes de Quebrada Honda continúan con estas prácticas productivas, aun cuando les sean evidentes los desequilibrios ecológicos ocasionados por el uso intensivo de los suelos. Hombres y mujeres manifiestan las dificultades actuales para trabajar tierras compactadas y dependientes de los agroquímicos, y hacen referencia también a tiempos anteriores, en los que "había más que hacer" y "había más variedad de alimentos". De este modo, las ventajas en el manejo de las prácticas productivas antiguas se contrapone al estrecho marco de acción que les impone la especialización productiva.

De los desequilibrios socio-ambientales percibidos surgen tres inquietudes: ¿qué caracterizaba las prácticas productivas que las familias de Quebrada Honda realizaban antes? ¿A qué lógica cultural correspondían dichas prácticas? Y, ¿qué tipo de paisajes

I. Este artículo es un desarrollo posterior a mi tesis de pregrado en antropología, titulada "Encrucijadas de una modernización urgente: procesos de transformación social de la alta montaña y el páramo, Quebrada-Honda, Cogua-Cundinamarca". En ella abordo con mayor amplitud aspectos que aquí menciono. La información presentada aquí fue recopilada durante mi trabajo de campo, hecho entre enero y junio de 2003.

entre enero y junio de $2003^{1}$. A partir de las vivencias de estos(as) habitantes, establezco una visión tentativa de las dinámicas modelaron? Este artículo busca responder estas inquietudes y definir las transformaciones que se produjeron desde comienzos del siglo veinte. Para ello recurro a los testimonios de algunas personas de mayor antigüedad en la vereda y a la observación en campo realizada 


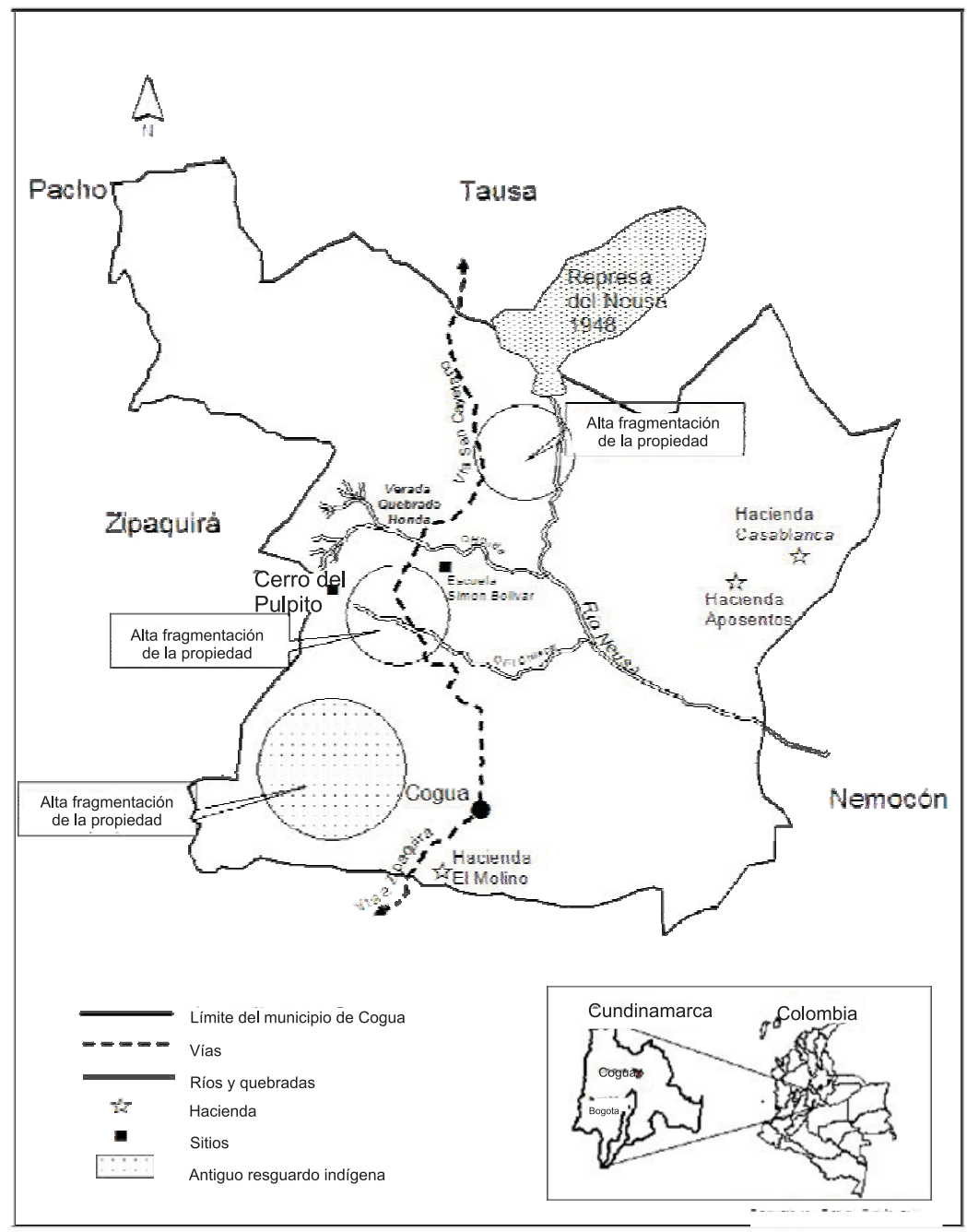

socioambientales en la alta montaña de la vereda de Quebrada Honda.

Para exponer los cambios identifico tres momentos distintos, de acuerdo con el papel que cumplieron en la historia local Santiago Rodríguez, Alberto García y Tránsito Hernández, antiguos 
habitantes de la vereda. La evocación reiterada de estos personajes me indicó algunas características de las relaciones sociales que se establecían dentro del territorio veredal en diferentes periodos de tiempo. También, la forma como las familias campesinas de Quebrada Honda vivieron los procesos históricos tendientes a la modernización del campo en Colombia y cómo los cambios se reflejaron en los paisajes de alta montaña. De este modo, en el texto doy cuenta de la adopción, combinación o sustitución de prácticas productivas, mientras que los personajes dejan en evidencia cómo la familia extensa, el trabajo asalariado y el aumento de la productividad de pequeña escala adquirían o perdían importancia en relación con la apropiación de los recursos y la transformación cultural y ambiental de esta sociedad rural.

Es importante mencionar que las personas con las que conviví durante el trabajo de campo y que me ayudaron en esta labor de reconstrucción, tienen edades entre cuarenta y setenta y cinco años. Buena parte de dichos habitantes nacieron en Quebrada Honda, aun cuando otros(as) llegaron allí a los dieciocho o veinte años de edad, procedentes de municipios del norte de Cundinamarca.

Mi estructura de análisis se basa en la articulación de los conceptos de apropiación, lógica cultural y paisaje. De acuerdo con Godelier (I984), el concepto de apropiación alude a las formas de acceso, uso y manejo de los recursos que establece el grupo social. Entiendo por lógica cultural la estructura de sentido que subyace a las prácticas y estrategias campesinas, mediante las cuales hacen uso de los recursos y manejan las restricciones ecológicas y las dificultades económicas. El paisaje, siguiendo a Duncan (1989), corresponde al modelo de cómo un entorno debe ser visto, lo cual incluye la distribución intencionada de elementos bióticos e infraestructurales. De este modo, al determinar las formas de propiedad de la tierra y las prácticas de apropiación de los recursos, establezco conectores de sentido entre los procesos de transformación de los entornos y las lógicas culturales de las familias campesinas.

En la primera parte del artículo contextualizo geográficamente el área de estudio y menciono las condiciones ambientales que la caracterizan. En la segunda hago referencia a los diferentes tipos de propiedad de la tierra que se formaron a lo largo del siglo veinte; señalo sus particularidades y doy un contexto histórico general en el que se consolidaron, además de mencionar los paisajes modelados en cada momento. En la tercera profundizo en 


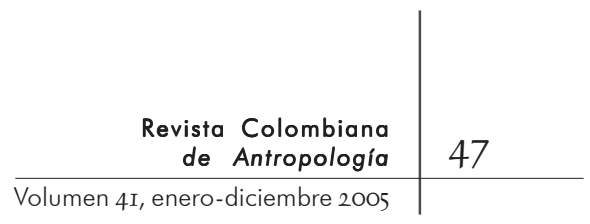

los paisajes modelados, mediante la descripción y análisis de las prácticas de apropiación y de las estrategias de manejo de los recursos para cada momento histórico local. Por último, analizo la lógica cultural de las familias campesinas, haciendo algunas reflexiones sobre su capacidad de adaptación al cambio, la importancia de valorar su experiencia con los ecosistemas de alta montaña y las razones de su continuidad en el campo.

\section{CARACTERÍSTICAS GEOGRÁFICAS \\ Y AMBIENTALES DEL ÁREA DE ESTUDIO}

L Municipio de Cogua, ubicado 52 Kilómetros de Bogotá, SE identifica porque en la fisonomía de su relieve se conjugan zonas planas propias de la sabana, zonas onduladas y zonas de alta pendiente. La vereda Quebrada Honda se encuentra localizada en la parte noroccidental del municipio, en límites con el municipio de Zipaquirá, y gran parte de su territorio está en la franja altitudinal correspondiente a la alta montaña ecuatorial, entre los 3.000 y los 3.600 metros sobre el nivel del mar (msnm). En dicha franja se encuentran, de forma ascendente, ecosistemas de bosque alto andino, subpáramo y páramo, con diferentes extensiones y en diversos estados de sucesión ecológica. Por sucesión ecológica se entiende el proceso de regeneración de la vegetación una vez se ha intervenido o modificado la estructura de los ecosistemas de un entorno particular (Sarmiento, I994). Por eso, las prácticas productivas en las zonas de altura han mantenido una dinámica constante de regeneración-modificación-regeneración. Así entonces, se debe tener en cuenta que el monte o charrasco al que hacen referencia los habitantes de la vereda corresponde a una vegetación arbustiva altoandina en proceso de sucesión. En tanto que la broza o chiquero corresponde a vegetación sucesional en áreas de subpáramo. Lo anterior es importante para la interpretación de las transformaciones de los entornos y la definición de los paisajes modelados mediante ciertas prácticas de apropiación de los recursos.

Entre las principales condiciones ambientales están el régimen bimodal de lluvias durante el año: fuertes de abril a mayo y de menor intensidad entre octubre y noviembre, así como una precipitación promedio de $978 \mathrm{~mm}$ anuales. Además, las variaciones 
de temperatura entre el día y la noche son frecuentes, lo que aumenta la frecuencia de heladas en los meses más secos (diciembre a enero). Estas son las condiciones ambientales que han manejado los pobladores de Quebrada Honda al habitar, trabajar y transformar los ecosistemas de alta montaña.

\section{DINÁMICAS EN LA FORMAS DE PROPIEDAD DE LA TIERRA EN COGUA Y QUEBRADA HONDA}

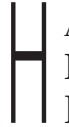
ABLAR DE LAS TRANSFORMACIONES SOCIOAMBIENTALES EN QUEBRADA Honda implica dar a conocer las prácticas de apropiación de los recursos, es decir, las formas de acceder, aprovechar o controlar el suelo, el agua o los recursos vegetales presentes en el territorio. Las prácticas de apropiación de los entornos de la sociedad rural coguana han estado determinadas por los sistemas de propiedad de la tierra vigentes en diferentes momentos de la historia local. Por su parte, los procesos políticos, económicos y culturales de la región, la nación y el mundo, han ejercido una mayor o menor influencia en la apropiación de los recursos y, por tanto, en el ritmo de las transformaciones de lo que hoy corresponde a la vereda de Quebrada Honda. En esta sección presento un contexto general de los tipos de propiedad que existieron en el municipio durante la primera mitad del siglo veinte, y esbozo las formas de propiedad de la tierra en la vereda y el tipo de paisaje que ayudaron a modelar. Esto último permitirá una lectura más acertada de los cambios en el entorno y la comprensión de las lógicas culturales de los habitantes de la vereda frente a estos procesos.

A principios del siglo veinte la mayor parte de la población coguana se distribuía en las áreas rurales, y se dedicaba, en general, a las actividades agropecuarias o de extracción de minerales. En ese entonces, las haciendas Aposentos, Casablanca y el Molino, ubicadas en la parte nororiental y sur del municipio, eran las propiedades de mayor tamaño (véase el mapa). Consolidadas desde mediados del siglo diecinueve, las haciendas del nororiente se articularon alrededor de la explotación del carbón, mientras las haciendas del sur se dedicaban a la ganadería y la producción triguera (Corporación Montaña Andina (Cormoan), 200I). 


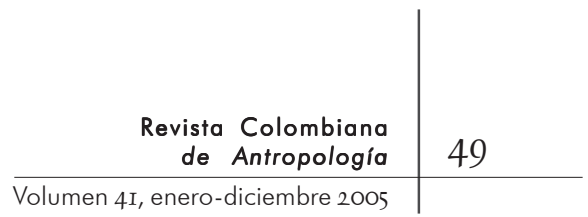

Por otra parte, en el lado sur occidental del municipio predominaban las pequeñas propiedades, en fuerte contraste con el tamaño de las haciendas. Tales propiedades se originaron por la subdivisión progresiva de predios formados en el siglo diecinueve, después de la subdivisión del resguardo indígena del pueblo de Cogua. De acuerdo con la información proporcionada por Velandia (1979), las tierras de resguardo de los indios cogua, nemeza y peza, adjudicadas por el oidor Miguel de Ibarra en el año de 1593 , se ubicaban en lo que hoy son las veredas Rodamontal y Barroblanco (véase el mapa). Debido a que la transformación de pueblo indio a parroquia se tornó en un pleito de más de veinte años, sólo en I842 los terrenos de este resguardo fueron liquidados y adjudicadas las escrituras correspondientes a cada beneficiario (Velandia, I979: 782).

Las tierras de la actual Quebrada Honda no recibieron la influencia directa del tipo de haciendas que se consolidaron en el municipio a mediados del siglo veinte ni de la segmentación temprana de la propiedad asociada a la subdivisión del resguardo indígena. Sin embargo, la vereda estaba inmersa en la compleja dinámica de concentración y fragmentación de la propiedad, correspondiente al periodo de consolidación de la propiedad absoluta y libertad en el uso de capital (Fals Borda, [I957] I973: I52). En el transcurso de la primera mitad del siglo veinte, en Quebrada Honda se produjo el fenómeno de fragmentación de la tierra, proceso que puedo explicar de un modo similar a como lo hizo Fals Borda para algunos municipios del departamento de Boyacá: "las explotaciones divididas han sido más bien el resultado del juego combinado de compras particulares y de herencias subdivididas entre familiares" (Fals Borda, [1957] 1973: 29). A lo largo del siglo veinte fueron notorios tres momentos de la tendencia a la fragmentación de la tierra en Quebrada Honda.

\section{Acumulación de tierras en la alta montaña}

D esde comienzos del siglo hasta i930, Quebrada Honda SE CAracterizó por un proceso de compras sucesivas de propiedades campesinas obtenidas por herencia, pero en proceso de titulación. Así, resultaron propiedades que alcanzaron las noventa fanegadas de extensión. En algunas de estas tierras, la apropiación 
de los recursos estuvo mediada por lazos de consanguinidad. Tal es el caso de las propiedades de don Santiago Rodríguez. En otras, existieron acuerdos tenenciales bajo la figura de arrendatario, campesinos o campesinas sin tierra que vivían en las grandes propiedades y trabajaban para el propietario. De acuerdo con Palacios (198I), este tipo de grandes propietarios hacían parte de una clase de campesinos ricos que se asentaban en las zonas de alta montaña, cuando las planicies eran apropiadas por haciendas.

En este periodo el paisaje fue modelado por la explotación de recursos vegetales de la alta montaña y por la apertura de áreas por encima de los $3.200 \mathrm{msnm}$, destinadas para los pastos que alimentaban animales de carga.

\section{Formación de fincas y pequeñas propiedades}

F NTRE I93O Y I960, EN LAS TIERRAS ACUMULADAS EN LOS AÑOS ANTEL riores se reanudó la dinámica de fragmentación de tres modos distintos: I) compras de tierra efectuadas por empresarios agrícolas procedentes de municipios adyacentes; 2) adquisición de pequeñas propiedades por parte de arrendatarios; y 3) subdivisión por repartición de herencias. Cada una de las modalidades de propiedad agraria originadas en este periodo se desenvolvía en el marco económico de un impulso moderado de modernización del campo tras el auge agroexportador (González, 200I). El marco político complementario estuvo representado, principalmente, por la ley 200 de I936, que establecía los parámetros de la explotación económica adecuada del suelo y definía las tierras baldías sujetas a expropiación. La subdivisión de las grandes propiedades de la parte norte de Quebrada Honda respondió a la incertidumbre que dicha ley produjo en los propietarios. De este modo, las tierras vendidas a los arrendatarios ocupaban áreas de cinco o seis fanegadas, mientras que las propiedades entre diez y cincuenta fanegadas pertenecían a herederos y, en menor medida, a propietarios recién llegados a la vereda.

El paisaje modelado durante este tiempo puede denominarse como policultivos de ladera. Algunos parches de bosque alto andino desaparecieron para darle paso al cultivo de cereales. El cultivo intensivo del trigo ocupaba las tierras ubicadas entre los $2.800 \mathrm{y}$ los 3.IOO msnm, y el monocultivo de la papa empieza a tomar auge. 


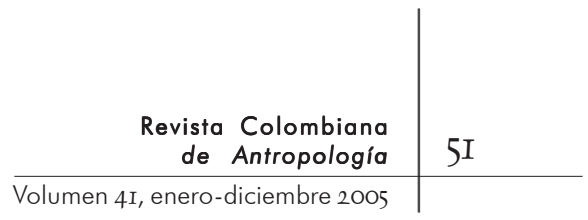

\section{Establecimiento de medianas propiedades y aumento de pequeñas}

$\bigcap$ e ESDE LA DÉCADA DE I960 EMPEZARON A DEFINIRSE LOS TIPOS DE propiedad actuales. Durante esos años muchos integrantes de las familias más antiguas se fueron de la vereda y buena parte de las tierras fueron sujeto de compraventas entre parientes. En ciertos casos, algunas personas heredaron más cantidad de tierras por ser hijos únicos, en tanto que otros debieron adquirir predios adicionales. De tal proceso surgieron tipos medianos de propiedad -entre diez y treinta fanegadas- y pequeñas propiedades de cinco fanegadas en diferentes espacios del territorio. Tanto la partida de grupos familiares como la fragmentación de propiedades se produjeron en el contexto de las políticas de desarrollo para los sectores populares y la consolidación de una agricultura tecnificada. Los estudios socioeconómicos de Cogua reiteran que en este periodo la mayoría de los productores del municipio eran propietarios. Señalan, además, el incremento de la superficie correspondiente a cada productor, ya que se involucraron "tierras que anteriormente no explotaban en forma técnica” (Cabrera y Rodríguez, I975: 60).

En este tercer momento de transformación los cultivos de papa y los pastos modelan el paisaje. El cultivo tecnificado de la papa se concentraba en propiedades ubicadas entre 3.200 y $3.400 \mathrm{msnm}$, y en las medianas y pequeñas propiedades los policultivos cedieron el espacio a los potreros para la manutención del ganado.

\section{Prácticas de apropiación \\ DE LOS RECURSOS}

\section{Las propiedades de Santiago Rodríguez $\mathrm{y}$ los recursos del monte (I9OO-I93O)}

F N LOS RELATOS SOBRE LAS PRIMERAS TRANSFORMACIONES DEL PAISAJE, $\sqcup$ la imagen de don Santiago aparece con frecuencia. La mayor parte de las personas coincide en que venía de los lados de Sutatausa, al oriente de Cogua, y que se trataba del gran propietario más antiguo en la vereda. Algunos lo recordaron por las vivencias que tuvieron a su lado cuando eran niños, y otros por lo que sus padres les contaban del abuelo, jefe de una familia 


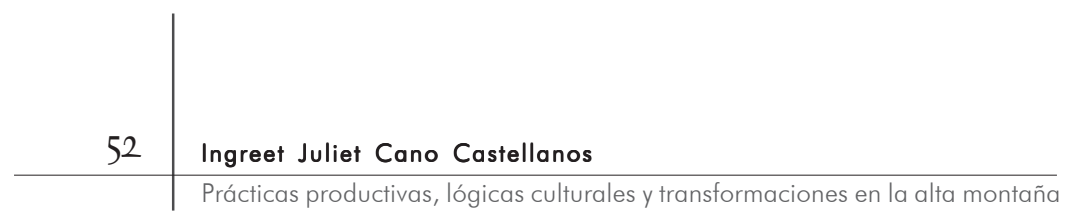

extensa de varias generaciones. Sin embargo, no todos valoraban de igual forma su papel como potentado y ancestro común. Juan Hernández, hombre de sesenta años dedicado en la actualidad a las labores agrícolas tras haberse pensionado de Álcalis de Colombia, recordaba a su abuelo por la forma hábil de obtener tierras de diferentes juicios de sucesión.

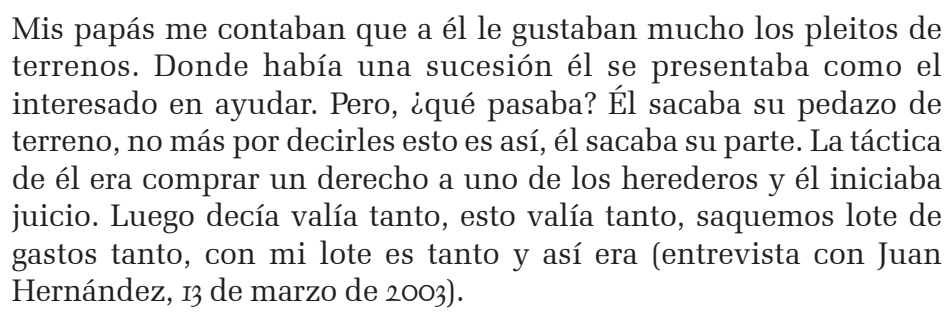
terrenos. Donde había una sucesión él se presentaba como el interesado en ayudar. Pero, ¿qué pasaba? Él sacaba su pedazo de terreno, no más por decirles esto es así, él sacaba su parte. La táctica de él era comprar un derecho a uno de los herederos y él iniciaba juicio. Luego decía valía tanto, esto valía tanto, saquemos lote de gastos tanto, con mi lote es tanto y así era (entrevista con Juan Hernández, i3 de marzo de 2003).

Hacia comienzos del siglo, don Santiago ya era dueño de las tierras del área que antiguamente se conocía como Paso del Ramo y que en la actualidad corresponde a la parte oriental de la vereda Quebrada Honda. Pasado un tiempo, don Santiago se casó con Hipólita González, hija de Jesús González y Carmen Hernández. Para aquel entonces, las propiedades de don Santiago, sumadas a las adquiridas durante el matrimonio, se extendían de la quebrada Honda hacia el sur hasta la antigua escuela Simón Bolívar, y desde este punto hacia la cima de la montaña, en cercanías del cerro El Púlpito (véase el mapa). Tal unión matrimonial fue el origen de una familia de diez hijos, cinco varones y cinco mujeres, de la que se desprendió buena parte de los habitantes de la vereda, muchos de los cuales han permanecido allí durante toda su vida.

Tal es el caso de Fidel Páez, también nieto de don Santiago e hijo de Marcelina Rodríguez y Álvaro Páez. Fidel, abuelo de sesenta y nueve años y trabajador del campo hasta el momento en que la artritis invadió su cuerpo, tuvo la oportunidad de conocer de cerca al jefe de la familia extensa. Las largas conversaciones que sosteníamos con Fidel, a quien le complacía hablar de los tiempos anteriores, me permitían observar los sentimientos de respeto y admiración que acompañaban los relatos sobre don Santiago.

Fidel trabajó desde muy corta edad para su abuelo, arriando mulas y bueyes de carga que transportaban la sal hasta el municipio de San Cayetano, a tres días aproximadamente. De regreso, ese mismo ganado traía la madera que se usaba en el proceso 


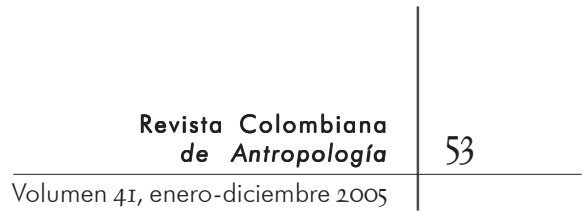

de evaporación del agua salina en las minas de Zipaquirá. Así entonces, la explotación de la sal articulaba los territorios del norte, como sucedía en tiempos prehispánicos (Rivera, I992).

Don Santiago obtenía excedentes económicos de dicho transporte de mercancías sin incurrir en mayores gastos, porque utilizaba mano de obra familiar y porque la manutención de los bueyes no requería la apertura de amplias extensiones de vegetación arbórea y arbustiva. Por tal motivo, como lo mencionó Juan Hernández, en las propiedades de don Santiago era muy poca la tierra destinada para pastos. Este tipo de práctica permitió que algunos parches o relictos de bosque alto andino permanecieran intactos por varias décadas.

La situación particular de perdurabilidad de vegetación alto andina en las grandes propiedades de comienzos de siglo veinte es un recuerdo frecuente entre los abuelos y abuelas de Quebrada Honda. Algo similar sucedía en las propiedades del señor Jorge Suárez, según Leuvigilda Zabala, campesina de setenta y cinco años de edad, quien había sido antigua arrendataria en las tierras del señor Suárez, al igual que su madre y su abuela, hasta que contrajo matrimonio y con su esposo adquirieron una propiedad de tierra en la parte nororiental de la vereda.

Además de recordar las intensas jornadas de trabajo, en las que ella y otras mujeres debían recolectar la leche que se utilizaba para preparar las cuajadas y los quesos, ella recordaba que las tierras del patrón, ubicadas hacia el norte de la quebrada Honda, se caracterizaban por la cantidad de monte que allí había y que impedía a los arrendatarios atravesar la propiedad.

De este modo, Fidel Páez y Leuvigilda Zabala vivieron su adolescencia rodeados de una vegetación arbórea y arbustiva que cubría varios sectores del territorio veredal, en áreas de subpáramo (3.100-3.400 msnm) y bosque andino (2.800-3.000 msnm). Encenillos, capes, tunos y tibares eran las especies que poblaban la parte media del territorio, espacio donde hoy se encuentran la carretera principal y gran parte de las casas campesinas. Fidel fue una de las personas de la vereda que me explicó detalladamente las causas de la desaparición o disminución de algunas de estas especies, relacionándola con el aprovechamiento intensivo de ciertas especies, para procesos industriales de pequeña escala. 


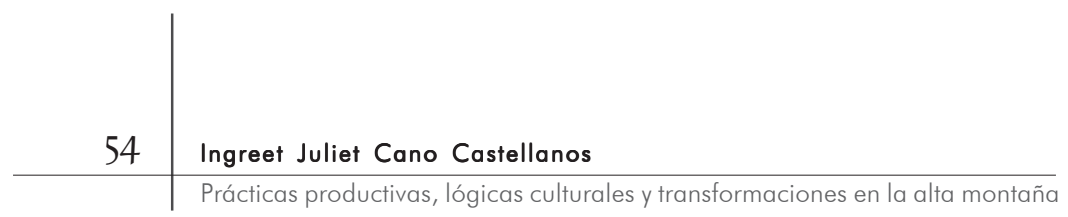

Antes los encenillos eran el monte aquí, pero la gente se robaba la cáscara, la corteza. Porque esa cáscara servía pa' curtir el cuero. Entonces se acababa la mata porque por intermedio del palo y la corteza va la savia y los nutrientes. Y eso por aquí [señalando los alrededores de su casa] por todo esto había de ese monte. Arriba [señalando la cuchilla a $3.600 \mathrm{msnm}$ ] había un poco de ese monte hasta abajo [2.700 msnm]. Y la gente era a rozarla y se acabó (entrevista con Fidel Páez, 22 de febrero de 2003).

La sustancia astringente o taninos con los que cuenta la corteza de este tipo de árboles no sólo llevó a la reducción de esta especie en el bosque alto andino de la vereda, sino también de otras del sur occidente. A comienzos del siglo veinte, estas sustancias eran usadas por grupos familiares que obtenían recursos económicos del curtido del cuero y que en la actualidad todavía viven de esta actividad (Cormoan, 200I).

El chusque fue otro de los recursos vegetales aprovechados por la población coguana en general, pero sobre todo por pequeñas familias campesinas de bajos recursos monetarios. El conocimiento sobre labores manuales, como el tejido con esta fibra vegetal, lo conservan abuelas de la vereda como María Delia Pachón y María Luisa Nieto, de ochenta y tres y setenta y seis años de edad, respectivamente. Durante su infancia y adolescencia, estas mujeres se dedicaron con sus familias al tejido de canastos de chusque, que vendían a los recolectores de sal de las minas de Zipaquirá. La señora Delia, quien con orgullo me enseñaba algunos de los canastos que aún conservaba, recordaba el momento en que la extracción de la sal dejó de ser una actividad de pequeños recolectores, razón por la cual la demanda de canastos disminuyó considerablemente y las familias tejedoras debieron buscar nuevas opciones de trabajo.

Las transformaciones sociales y ambientales relacionadas con el proceso productivo de la sal son recordadas por varios habitantes de Quebrada Honda y otras veredas. Así lo manifestaba Gonzalo Cruz, antiguo habitante de la vereda Rincón Santo y miembro de una familia de líderes campesinos, al recordar la abundancia del chusque en los paisajes de la alta montaña y al analizar el aparente papel secundario de la cestería para la sociedad rural coguana. 


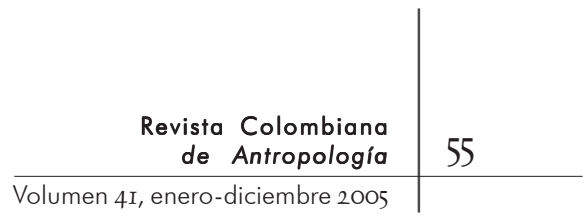

Cuando mis padres necesitaban hacer cualquier construccioncita o hacer para sus servicios canastos, entonces íbamos a buscar lo que llamaban chusque. Pero es que uno no podía entrar y en esa cima había agua que era un placer. Una industria que tuvo Cogua además de su agricultura y su ganadería, de lo que siempre tenemos el sonsonete, fue la hechura de canastos particularmente para el secamiento de la sal. Aquí hubo bastante gente que se sustentó y pasó su diario de hacer canastos. La gentecita vivía de eso. Cómo estaría de poblado eso de buen chusque (entrevista con Gonzalo Cruz, 5 de abril de 2003).

$\mathrm{Al}$ evaluar este conjunto de actividades son evidentes situaciones contrastantes que es preciso interpretar. Por una parte, el aprovechamiento del chusque y el uso de la corteza del encenillo por parte de campesinos sin tierra o pequeños propietarios tuvieron un fuerte impacto en la vegetación arbórea y arbustiva del bosque alto andino. Por otra, la apertura de claros de bosque para el pastoreo de bueyes y ganado vacuno en amplias propiedades tuvo también fuerte impacto, que, sin embargo, posibilitó la perdurabilidad de parches de vegetación primaria.

Si se piensa en la lógica cultural que enmarcaba estas prácticas, se podría afirmar que sobre los recursos del monte no se ejercía el mismo control que sobre el recurso suelo, en el que basaban su poder grandes propietarios, como don Santiago. De ahí que fuera posible que casi cualquier campesino se metiera entre el monte y tomara los recursos que necesitara. Además, es posible que para las familias campesinas la abundancia relativa de las especies vegetales mencionadas no hiciera urgente la necesidad de controlar el uso de los recursos de los que dependían económicamente.

Las prácticas alimenticias de los habitantes de Quebrada Honda modelaron también el paisaje veredal. La dieta de la papa y el recao -nombre que recibe la combinación de varios tubérculosera tan antigua como la agricultura del fuego, técnica para cultivar estos alimentos. Estas actividades, utilizadas por los indígenas y luego mestizadas por la combinación con elementos tecnológicos de la cultura hispana, se hacían en las partes más altas de Quebrada Honda, en áreas donde crece la vegetación de arbustales y rosetales del páramo andino (De Robert, I994), que corresponde a lo que en la vereda llaman la broza o el chiquero. Entre este tipo de vegetación se hacían las huertas de chuguas, cubios, ibias y papa. En diciembre, tiempo que coincide con la 
época seca, se rozaba y se quemaba, en tanto que la siembra se hacía a finales de febrero, es decir, hacia el final de esa época. Mientras el periodo de descanso comprendido entre la quema y la siembra permitía aumentar la disponibilidad de nutrientes, la época seca ayudaba a disminuir el riesgo de heladas.

Según recuerdan las personas de mayor edad, el cultivo de tubérculos era una práctica generalizada de las familias de Quebrada Honda, que destinaban las cosechas al autoconsumo. En la recolección de papas, chuguas e ibias se utilizaban los ganchos o garabatos, que permitían conservar la mata. De este modo alcanzaban a tener tres cosechas de una sola siembra, que aseguraban la alimentación por largo tiempo. La toya y la retoya, como se llamaba localmente a la primera y segunda cosecha de tubérculos obtenidos por este sistema, permitían una mínima inversión de trabajo y el uso de una misma semilla para un periodo relativamente amplio. Así lo mencionaba Fidel Páez, al recordar la antigua forma de trabajar la tierra.

La papa daba unas tres cosechas. La llamaban: el cultivo, la toya y la retoya. Lo mismo la chugua y lo mismo la ibia. Ahora diga usted, otra de las cosas era que eso la sacaban con unos ganchos para no cortarla. Ya le digo, con cuidado era que se sacaba. En ese tiempo se recogía por parejo que llaman todas tres: gruesa, pareja y richa y ajunte, tal como sale de la mata (entrevista con Fidel Páez, 22 de febrero de 2003).

Sin embargo, con el tiempo la dinámica de sucesión vegetal modificada con la rocería, la quema y la siembra llevaron a la población de Quebrada Honda a intensificar la apertura de nuevas rozas o huertas en las áreas de frailejonal-pajonal del subpáramo y páramo, con el fin de obtener tubérculos de un tamaño considerable. La aparición de la maleza conocida como hierba colorada llevaría a la disminución de las cosechas producidas en una misma huerta. Es probable que la aparición de dicha planta estuviera reflejando la volatilización de nutrientes, efecto asociado a las quemas (Sarmiento, 1994; Vargas, 1990).

Del sistema de manejo de los recursos alimenticios utilizado anteriormente destaco que la lógica cultural campesina relacionada con el ajuste del calendario agrícola habla de las dificultades ambientales en las áreas de montaña y de la experiencia heredada de los más antiguos. Por otro lado, la modalidad de producción de cultivos subsiguientes de papa evidencia una lógica 


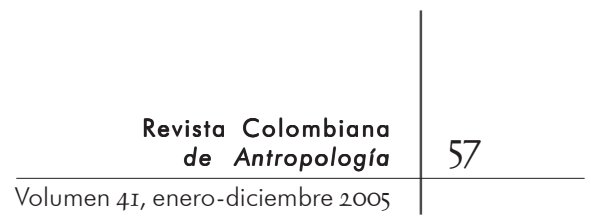

cultural campesina en la que el aumento de la productividad no pesaba tanto como la necesidad objetiva de garantizar la reproducción de los recursos.

Los claros para el aprovechamiento de recursos comercializables, los potreros para animales de carga y las brozas en diferentes estados de sucesión ecológica, modelaban entonces un paisaje que poco a poco empezaba a perder la diversidad en los bosques y presentaba modificaciones continuas en los ambientes de subpáramo y páramo.

La importancia del ganado durante este primer momento de transformación del entorno radicaba en que era la única fuente de fuerza de trabajo no humana utilizada para el transporte de recursos. Sin embargo, se le adjudicaban otros valores, relacionados con el prestigio social, que sustentaba el poder de ciertos propietarios. En lo que sigue iré evidenciando cómo el ganado puede considerarse el elemento constante en los procesos de transformación socioambiental de la alta montaña en Quebrada Honda. De este modo, el valor otorgado al ganado fundamenta una serie elementos significativos de la lógica cultural de las familias campesinas, que propenden específicamente a la reproducción de los recursos que les garantizan su continuidad como grupo social.

\section{Don Alberto García y el verdadero trabajo de la agricultura (I930-I960)}

U ACIA PRINCIPIOS DE LOS AÑOS I94O EL PAISAJE VEREDAL EXPERIMENП tó un nuevo tipo de transformación. Para esos tiempos, el poder estructurante de don Santiago se difuminaba entre la trama de relaciones de parentesco de las familias herederas, que daban otro sentido a la distribución de la propiedad en el contexto veredal. Las fincas mayores de diez fanegadas se hallaban en la parte central de la vereda, contiguas a la quebrada Honda. Las pequeñas propiedades de cinco y diez fanegadas estaban en la parte nororiental del territorio en dirección al río Neusa, y en la parte sur cerca de la quebrada el Chuscal. En las propiedades del norte la fragmentación respondía a la parcelación de grandes propiedades, como las de Jorge Suárez, quien vendió las tierras a sus trabajadores. La fragmentación en el sur se produjo por la distribución de la tierra de propiedades de menor tamaño. 


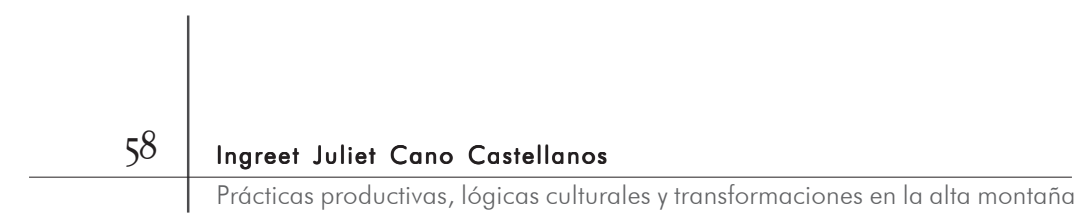

Con la presencia de nuevos actores en Quebrada Honda se produjeron otras variaciones. El ejercicio de poder sobre los recursos a partir de su transformación adquirió mayor valor entre las familias campesinas de la vereda con la llegada de Alberto García. Por lo general, los recuerdos sobre este personaje están asociados a la imagen de un campo que se transformaba mediante el trabajo agrícola de mayor escala. En los relatos la palabra agricultar es utilizada para diferenciar esta nueva práctica del trabajo hecho en las rozas. En este sentido, los cambios adoptados en la vereda aceleraban notablemente el ritmo de las transformaciones de los paisajes.

Nacido y criado en Tausa, don Alberto García adquirió varias fincas de la parte norte de la vereda, en las que complementaba la agricultura y la ganadería. Sin embargo, aquello por lo que más lo recuerdan es por los extensos cultivos de trigo en los que invertía grandes cantidades de dinero para pagar obreros y máquinas trilladoras. La señora Fidelina Montaño, de ochenta y tres años de edad, trabajó durante quince años para don Alberto, asistiendo la alimentación de los obreros, de tal forma que fue testigo de la transformación que se produjo.

Además, en sus relatos se vislumbra la influencia que ejerció el primer gran productor agrícola de Quebrada Honda.

Todo eso dizque era monte. Pero hasta que llegó don Alberto García. Era que nadie desmateaba una mata, ni araba ni sembraba, hasta que llegó don Alberto García y les enseñó a arar y sembrar. Y ahí sí todo el mundo are y siembre. A hacer potreros por ese lado, donde llaman la vuelta del Cape. Es que ahí [señalando la carretera central] había unos capes grandísimos y por ahí quedó la mata de cape. Eran unos matonones con unas hojas grandísimas (entrevista con Fidelina Montaño, 23 de marzo de 2003).

Con los cultivos de trigo en las partes medias y con las huertas de papa en el páramo se produjo en la vereda algo que Monasterio (I980) denomina sistema agrícola mestizado -cereales-tubérculos- representativo de la época colonial e independentista. Las condiciones ambientales propias de la alta montaña tropical posibilitaron la coexistencia del trigo y los tubérculos en nichos agroecológicos separados, tal y como sucedía en el periodo colonial. La coexistencia de estos dos sistemas productivos fue una pequeña fase de transición hacia la 


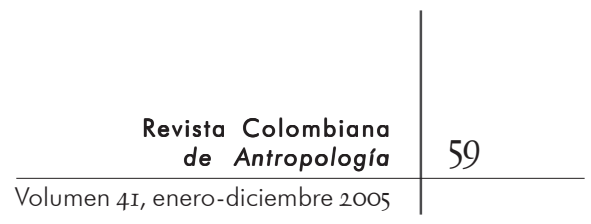

intensificación agrícola. Durante este periodo aún se cultivaban las chuguas, ibias y nabos, propios de la dieta campesina, especialmente por parte de los pequeños propietarios, mediante la roza y quema del pajonal-frailejonal.

Don Alberto rotaba el trigo con extensos cultivos de habas, de tal modo que los tiempos de barbecho se acortaban y la mano de obra requerida en el proceso productivo aumentaba. Así entonces, la mayor parte del año el paisaje en Quebrada Honda se encontraba con cultivos en diferentes momentos de su desarrollo, tal y como se aprecia en una fotografía de la vereda. En ella se ve cómo los trigales y los cultivos en asocio de habas y arveja están atravesados por tres personas que llevan en andas al Divino Niño, quizá con motivo de las procesiones que se hacían en diciembre (véase la fotografía). De este modo, la celebración de las fiestas religiosas y el tiempo de recolección de las cosechas producían un ambiente de plena abundancia, que personas como la señora Fidelina recordaban con admiración.

Ahí donde es la casa de don Fidel Páez era donde trillaban el trigo, todo eso de para arriba eran esos trigalotes y ese pilón de máquinas pa' trillar. iiiUyyy!!! Eso él echaba hasta cuarenta obreros, era un gentío. Llegaban obreros por allá de Páramo Bajo de por allá arriba de San Antonio, El Salitre. Sembraba habas allá abajo en la orilla de la quebrada [Honda] y de ahí pa' arriba, qué haberos, virgen santísima (entrevista con Fidelina Montaño, 23 de marzo de 2003).

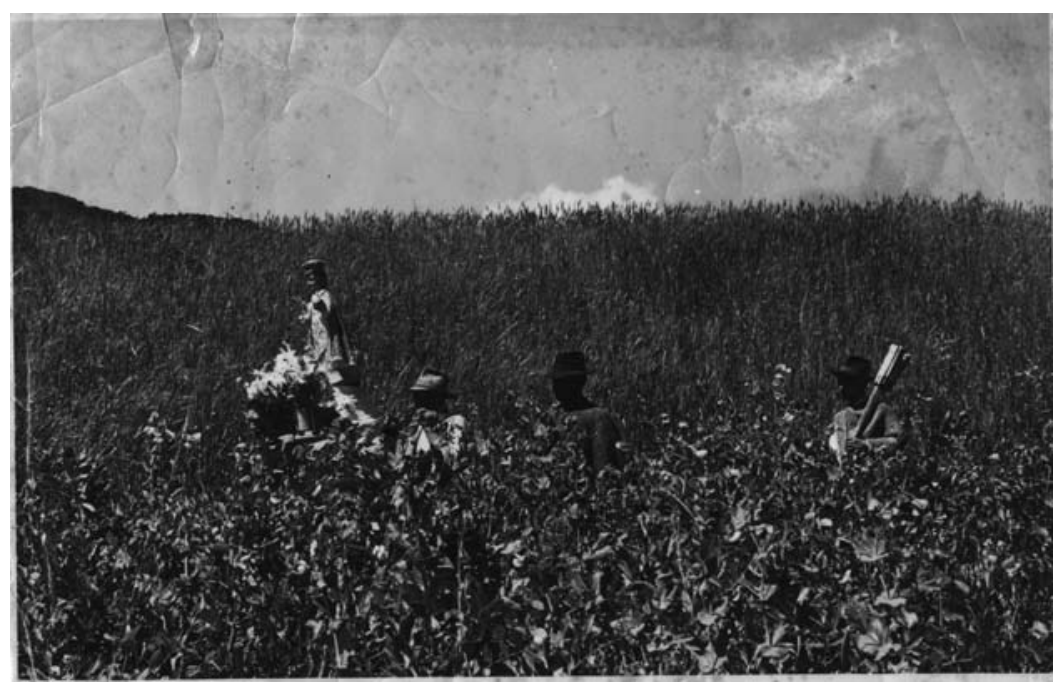


Los propietarios menores, por su parte, rotaban los pastos para el ganado con cultivos de papa, haba y, en menor medida, arveja. Es probable que el uso de grandes extensiones de tierra, el poco acceso a las trilladoras y la escasa posibilidad para contratar obreros fueran algunas de las razones por las que muchos propietarios en Quebrada Honda permanecieron al margen de la producción triguera, orientándose más bien hacia el cultivo de la papa y la manutención del ganado vacuno.

Mencionar algunas características del manejo que le daban las familias campesinas de Quebrada Honda al cultivo de la papa permite evidenciar la conservación de sus conocimientos sobre los procesos ecológicos de la alta montaña. Teniendo en cuenta que precipitación y frecuencia de heladas siguen tendencias opuestas, la papa de año se sembraba en febrero, tal y como se hacía con el sistema de roza y quema. La tierra se dejaba descansar por lo menos diez años, de modo que había espacio para la sucesión-regeneración de vegetación, útil en la recuperación de la fertilidad de las tierras. Y aun cuando la yunta de bueyes se usaba en diferentes momentos del proceso productivo, según recuerda Marina Duarte, campesina de sesenta años de edad, "se trabajaba más al azadón” y los garabatos continuaban utilizándose en la recolección de los tubérculos.

Por otra parte, los recuerdos sobre la utilización de los abonos orgánicos están asociados a los recuerdos sobre la menor escala a la que obedecía el cultivo de la papa. Varias personas también recuerdan las primeras enfermedades de los cultivos y el uso de los primeros fertilizantes químicos. De esta manera, hombres y mujeres empezaban a evidenciar las difíciles condiciones a las que estaba sujeta la producción de papa en su proceso de transición hacia una agricultura a escala comercial. José Ballesteros, campesino de sesenta y un años de edad, analizaba con frecuencia en las conversaciones los cambios y las dificultades que él ha experimentado como pequeño productor de papa.

Primero no sembraban en cantidades como siembran ahora. La papa se sembraba con abono orgánico, abono de res o de oveja. Lo amontonaban y después con una varita se ponían a darle palo, que quedara eso como harina. Y después se recogía el estiércol y se lo echaban a los cultivos de papa o de haba, o lo que fuera. Con eso era más que suficiente. Ahora, no se conocía el gusano blanco por ahí en los años cuarenta y cincuenta. No se conocía la gota. Era sanita la papa, siémbrese donde se sembrara (entrevista con José Ballesteros, 8 de marzo de 2003). 


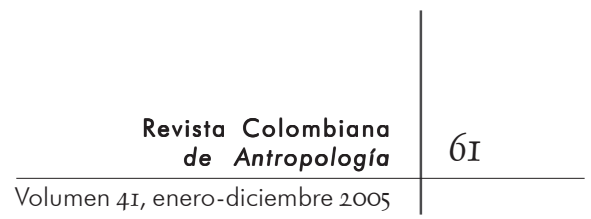

Durante esta fase de policultivos se empezaron a utilizar las mismas tierras para los cultivos de trigo y papa en rotación, lo que contribuyó a la disminución del tiempo de descanso de la tierra e influyó en la menor calidad de las cosechas de trigo. La gente en la vereda asocia la disminución y posterior desaparición de los cultivos de trigo con la aparición del polvillo, al parecer enfermedad común en varios lugares del altiplano cundiboyacense (Fals Borda, [1957] 1973). Así como el trigo, los tiempos de abundancia para don Alberto García también entraron en receso. Los últimos recuerdos de este personaje refieren a la grave crisis en que cayó y las disputas entre los hijos por lo que quedó.

En la actualidad, varias investigaciones han evaluado la interrelación entre tiempos largos de descanso de la tierra y procesos de sucesión-regeneración vegetal, propios de la agricultura tradicional campesina, demostrando su importancia en la acumulación de nutrientes y en la posibilidad de mantener un equilibrio entre ecosistemas y agroecosistemas de altura (Sarmiento, I994; De Robert, 1994). De este modo, que las familias campesinas de Quebrada Honda optaran por el cultivo de la papa puede ser visto como una estrategia para manejar condiciones ambientales restrictivas y como una forma de aplicar sus conocimientos sobre los procesos de sucesión vegetal en los barbechos.

Por otro lado, la formación de medianas propiedades y el mayor uso agrícola de la tierra estuvo acompañado del aumento de cabezas de ganado vacuno. De este modo, la agricultura proveía el forraje para el ganado y éste favorecía la fertilización orgánica de la tierra. Además, al vender los quesos y la mantequilla de la producción lechera, las familias campesinas complementaban los rubros obtenidos de un trabajo agrícola, no tan orientado al aumento de la productividad. La apertura de extensas áreas para los cultivos y la más o menos constante cobertura de pastos modelaron el paisaje hacia finales de los años I950.

\section{Aumentar la productividad para el desarrollo: Tránsito Hernández y el Movimiento de Reconstrucción Rural (I960-I980)}

ON EL SISTEMA DE POLICULTIVOS TANTO EN LAS GRANDES FINCAS COMO $\zeta$ en las pequeñas propiedades, las transformaciones del paisaje 
en Quebrada Honda se aceleraron significativamente. La tendencia a la fragmentación de la tierra era más evidente en los asentamientos del sur, donde el principio de "herencia partible" cumplía su función. La familia campesina siguió siendo el eje central de la sociedad veredal, sobresaliendo algunas personas pertenecientes a las familias más antiguas, en torno a las que se articulaban procesos comunitarios. Conocidos(as) como alférez, estos personajes se convirtieron en los intermediarios de los programas de desarrollo para las sociedades rurales de Colombia, a partir de la década de ig6o. Tal fue el caso de la señora Tránsito Hernández, esposa de Francisco Rodríguez, nuera de don Santiago y líder femenina de la vereda.

A continuación analizo las transformaciones del paisaje y la adopción de nuevas técnicas de producción, teniendo en cuenta con más detalle los procesos políticos, económicos y culturales nacionales e internacionales. Así mismo, doy cuenta del proceso acelerado de deterioro de los recursos y los desequilibrios sociales, contrarios a los presupuestos de los programas de desarrollo rural.

La mayoría de habitantes recuerda a la señora Tránsito por la organización de actividades culturales, religiosas y políticas en la vereda. Además, su viaje al Paraguay con motivo del seminario sobre la "Incorporación de la mujer campesina en el desarrollo de su comunidad", fijó su imagen en la memoria de las familias campesinas. Cuando visite por primera vez Quebrada Honda, en 2003, ella había fallecido hacía cuatro años. Por eso, el encuentro no fue inmediato, sino que estuvo relacionado con mis inquietudes sobre el momento histórico local en el que se adoptaron los agroquímicos, que de acuerdo con varios habitantes se había caracterizado por la frecuente organización de actividades comunitarias. Poder acceder al cúmulo de documen-

2. Se trata de varios folletos, cartillas, revistas y afiches, cuyas fechas oscilan entre finales de los años I950 y comienzos de la década de I970, producidos por entidades estatales y eclesiásticas, además de algunos escritos personales y fotografías. Un análisis sobre la importancia de la imagen en estos documentos y su relación con la promoción del cambio social y tecnológico puede consultarse en Cano (2004).

Poco a poco fui concluyendo que la salida de una mujer de la vereda fuera del país en el año de I97I, la instalación del alumbrado tos ${ }^{2}$ que ella recopiló y conservó durante buena parte de su vida me permitió conocerla en detalle y me ayudó a establecer la fuerte conexión que se daba a mediados de siglo veinte entre los mundos rural y urbano, en Colombia y en el mundo. 


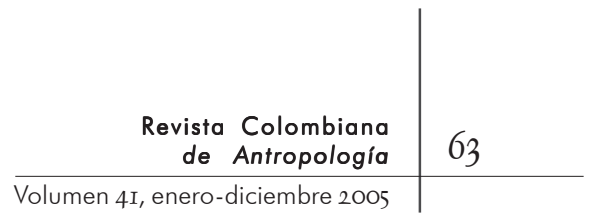

público en 1968, la presencia de carros lecheros desde 1963 y el arriendo de la finca de la difunta Fermina Cubillos para cultivos de papa en I970, fueron acontecimientos que se produjeron bajo el contexto de las políticas de modernización del campo y el campesinado. Mientras la modernización del campo proyectaba la tecnificación agrícola, la organización y el trabajo comunitario permitirían suplir las necesidades colectivas e incrementar el nivel de vida de la población rural (González, I973).

En esta trama de programas y proyectos para el desarrollo rural, la expresión "aumento de la productividad" se convirtió en un "lugar común" de los discursos de las entidades estatales creadas a lo largo del siglo veinte ${ }^{3}$. Con esta expresión se aludía a diferentes prácticas campesinas que se consideraban contrarias a la promoción del desarrollo y que, por tanto, debían ser cambiadas. Entre ellas estaban la gran cantidad de tiempo invertido en el proceso productivo, el poco rendimiento de las semillas utilizadas y el uso del sistema de roza y quema. La lógica cultural que subyace algunas de estas prácticas ya ha sido expuesta, por lo que 3. Para una visión del proceso histórico de las entidades vinculadas con la modernización de la agricultura, véase: González (200I). sólo debo añadir que en ese momento histórico la modernización de la agricultura era un proyecto inaplazable. De este modo, la Caja Agraria, el Instituto Colombiano Agropecuario (ICA) o el Instituto Colombiano para la Reforma Agraria (Incora) defendieron la necesidad de utilizar los insumos químicos, las semillas mejoradas y los créditos financieros, que por disposición del estado estaban autorizadas a ofrecer (González, 200I).

Durante este periodo de auge institucional la iglesia católica también hizo su aparición. Ligada con las políticas de desarrollo para los países del tercer mundo, esta institución empleó sus fuertes vínculos con el campesinado para suscitar la transformación de algunas prácticas productivas. En Colombia, la Acción Cultural Popular (Acpo) cumplió este papel, mediante la emisión radial y la publicación de varios materiales dirigidos al campesinado. La señora Tránsito, miembro activa de las Escuelas Radiofónicas de la Acpo, se encargó de difundir en Quebrada Honda algunos de los materiales que le eran entregados. En ellos no sólo es posible analizar el discurso de la Acpo sobre la necesidad del cambio tecnológico, sino también su forma particular de comunicarse con sus lectores. 


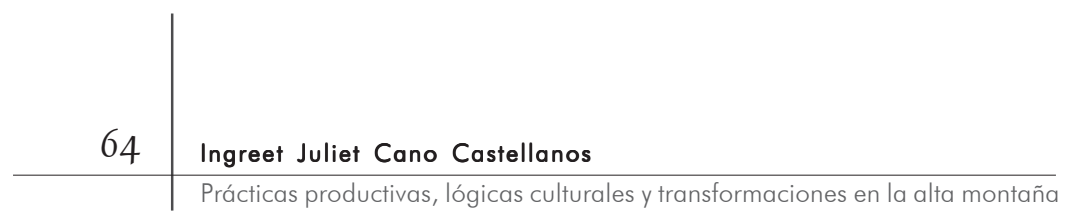

Ustedes ya saben que así como deben instruirse en las cosas de nuestra santa religión, de las letras y la cultura general, así también deben prepararse en las cosas de la tierra, que es la fuente de su economía y de la economía de la nación (...) la vida de la nación está íntimamente ligada a esos 20 ó 40 centímetros de capa vegetal. Es necesario producir más. Así lo quiere la Iglesia, así lo pide la Patria (...) Estas enseñanzas son como semillas; ustedes, amigos campesinos, son como la buena tierra donde han de germinar y dar fruto (Cursos campesinos, Acpo: I95?).

Por otra parte, en 1965 inició actividades en Cogua el Movimiento Colombiano de Reconstrucción Rural (MCRR), organismo promotor de los programas de modernización en los municipios. El MCRR fortaleció la labor educativa del campesinado iniciada por la Acpo, y para ello encontró apoyo fundamental en la señora Tránsito, quien asumió con ahínco su papel de líder comunitaria.

Además, el MCRR se encargó de dar a conocer la forma como la tierra podía ser "productiva y explotada en forma económica y racional". Estableció contactos con las diferentes entidades estatales que podían ofrecer los servicios técnicos y financieros necesarios para que los pequeños y medianos agricultores adquirieran los insumos químicos y aprendieran a utilizarlos. Puso en práctica también algunos proyectos agrícolas en diferentes veredas, con el ánimo de enseñar al campesinado algunas técnicas de cultivo. Las reflexiones de don Gonzalo Cruz acerca de las actividades del MCRR dejan en evidencia las tensiones culturales que se produjeron en la transición hacia el sistema de monocultivo y fertilizantes.

Ese movimiento decía que había que echarle esto y lo otro. Que la semilla, que eso es respetable, tenía que ser con el ojo para arriba la papa y la distancia y eso no (...) Y los otros que caramba a como era su sistema antiguo con sus bueyes de yunta y demás. Pero claro eso era aceptarles porque ellos venían a tratar de que se actualizara uno, sino que el sistema que ya había no se podía eliminar de un momento a otro (entrevista con Gonzalo Cruz, 5 de abril de 2003).

Se aprecia entonces que en el encuentro de sistemas tecnológicos subyacía el encuentro de lógicas culturales, que ponía en juego la autoridad sobre el conocimiento. Según este líder y analista de la historia local, la adopción de las tecnologías químicas 


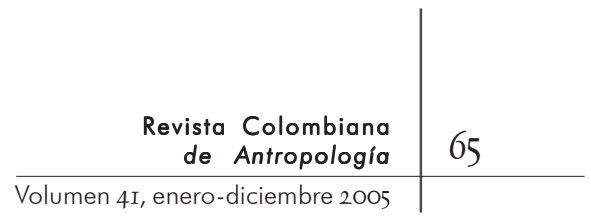

no se produjo de un momento a otro. Si bien los medianos y pequeños propietarios ya llevaban un tiempo de conocer el Nifoskal, abono ofrecido por la Caja Agraria, hacia finales de los años I960 aún no habían adquirido el hábito de cultivar con productos químicos. Para adoptar los paquetes tecnológicos, los campesinos debieron comprobar la efectividad de los insumos y empezar a creer en la necesidad de obtener una mayor producción.

Manuel Rincón, campesino de setenta y dos años, se estableció en Quebrada Honda a sus dieciocho años de edad, cuando le compró un pedazo de tierra a Estella González, sobrina de la esposa de don Santiago Rodríguez. Después de trabajar como obrero agrícola en haciendas del municipio de Tausa, finalmente pudo dedicarse con su esposa a trabajar "En lo propio", en un predio de aproximadamente dos fanegadas. De este modo, a medida que en la vereda se producía la intensificación agrícola, él sumaba esfuerzos para consolidarse como pequeño productor de papa. Con base en su experiencia adquirida en el negocio de la papa, afirmaba que la llegada de grandes productores provenientes de Río Frío (Zipaquirá), influyó en la adquisición generalizada de insumos químicos en la vereda.

Eso ellos ["los paperos"] no le echan el abono en el centro del hoyo sino en redondo para que no se le dañara la semilla porque salía muy fuerte, muy bravo. Se lo echaban para que diera producto mejor, para engruesar la papa. Y por ejemplo si primero a uno le reportaba por ahí un diez ${ }^{4}$, con ese químico ya daba hasta un quince o un veinte. Entonces no ve que

4. Número de cargas obtenidas por carga de semilla sembrada. Una carga son dos bultos. siempre daba harto mejor. Por eso la gente se acostumbró a que todo el mundo debía usar abono (entrevista con Manuel Rincón, I2 de febrero de 2003).

La abundancia que el campesinado en Quebrada Honda empezó a ver y a relacionar con la utilización de fertilizantes químicos radicaba, por un lado, en la reducción del periodo de descanso de la tierra a unos cuantos años y, por otro, en la posibilidad de cultivar más años consecutivamente. Sin embargo, las labranzas continuas, las cosechas seguidas y los cultivos sin ninguna cobertura provocaban la compactación del suelo (Sarmiento, 1994). Con las nuevas técnicas era necesario también contar con capital líquido para adquirir fertilizantes y semillas, y para contratar obreros en los tiempos de recolección. 
Por otra parte, la manutención de ganado vacuno empezó a realizarse también de acuerdo con los parámetros del "aumento de la productividad". La leche, que antes se usaba para la fabricación casera de quesos y mantequilla, se empezó a vender a pequeños comerciantes de fuera de la vereda. Ahora bien, si se tiene en cuenta que el ganado era la opción menos riesgosa, durante este periodo muchos propietarios en Quebrada Honda optaron por seguir cuidando de sus vacas, como estrategia segura de articulación con los monocultivos.

Con la modernización agrícola los costos de producción se sumaron a los factores ambientales extremos. Frente a esta situación las familias campesinas sólo tuvieron dos opciones: o incurrir en los gastos necesarios para obtener cosechas comercializables o, en su defecto, arrendar las propiedades y dejar que otros asumieran la totalidad o parte de los gastos. Arrendar la tierra a los productores de papa de la región se convirtió en la estrategia que permitía obtener pastos para el ganado con una baja inversión de trabajo y capital. Fidela Hernández, líder femenina de cuarenta y nueve años de edad y sobrina de la señora Tránsito, analizaba de este modo las causas al arrendamiento de varias fincas, dejando en evidencia la estrategia y la modalidad de trabajo a la que tendió el uso agrícola de la tierra en Quebrada Honda.

\footnotetext{
Los que empezaron a cultivar en grande ya no eran de aquí, se les empezó a arrendar la tierra porque los potreros ya no pastaban. Empezaron a arrendar por aquella finca que uno llama de la difunta Fermina de Cubillos. Donde era el puesto de salud. Esa fue la primera que arrendaron y eso hubo papa a todo dar (entrevista con Fidela Hernández, I9 de marzo de 2003).
}

Los insumos químicos usados en los cultivos de papa durante dos o tres años dejaban la tierra abonada y propiciaban el crecimiento de los pastos. De este modo, las familias campesinas garantizaban el alimento para el ganado y, por consiguiente, la producción lechera.

Hacia finales de los años I970, el paisaje se caracterizaba por la reducción del tiempo de descanso de la tierra -de diez a dos años-, por unos suelos dependientes de los insumos y por el uso intensivo de tierras por encima de los 3.400 metros de altura, por parte de los grandes productores de papa. El ganado se acopló a 


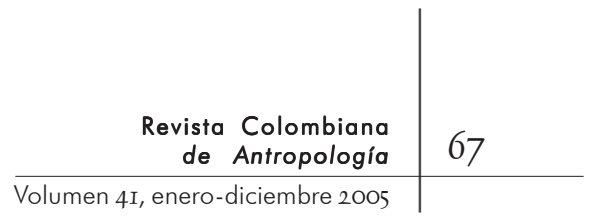

las variaciones en el uso de los suelos y se mantuvo casi incólume frente a las condiciones ambientales difíciles, particularmente las heladas. Los procesos comunitarios promovidos localmente por el MCRR pasaron casi a un tercer plano, cuando la tecnificación agrícola era prácticamente un hecho y cuando la monetización de las economías campesinas mitigaba los propósitos del desarrollo rural. Con la salida del MCRR del municipio, la señora Tránsito tuvo menos actividades que asumir y finalmente volvió a la vereda a ocuparse de los asuntos menores de la comunidad.

Actualmente, la dinámica del paisaje no ha sufrido cambios trascendentales, aun cuando los desequilibrios ambientales no cesan y se manifiestan en los cambios climáticos, la mayor frecuencia de las heladas y la aparición de nuevas plagas en los cultivos. Por otra parte, la tendencia al cuidado del ganado se mantiene, aunque los pastos secos durante el verano reducen la producción lechera, de la que vive gran parte de las familias campesinas. De todas maneras, la posibilidad con la que algunos cuentan, de tener predios en distintos lugares y a diferentes alturas, les permite sobrellevar la carencia de pastos en los veranos intensos.

Termino así este recorrido por las prácticas productivas de las familias campesinas de la vereda y por los paisajes modelados en cada tiempo. Ahora es posible observar con nuevos ojos el paisaje actual y comprender mejor las estrategias que usan las familias campesinas para contar con los recursos necesarios, a pesar de las difíciles condiciones económicas que les impone la modernización agrícola.

\section{Tendencias actuales Y REFlexiones FINALES: EL GANADO ES GANADO}

N O HAY QUE DUDAR DE LA EXPERIENCIA DE UN CAMPESINO O CAMPEsina cuando dice que "el ganado es ganado". En este largo proceso de apropiación de los recursos de los ecosistemas de la alta montaña las familias campesinas se han percatado de las posibilidades que ofrece la manutención del ganado, frente a las condiciones económicas y ecológicas cada vez más extremas. La poca vulnerabilidad a las heladas, la baja demanda de mano de obra, el escaso requerimiento de insumos agropecuarios y el hecho de 
garantizar una entrada fija de dinero son algunos de los factores que permitieron que la ganadería se mantuviera constante en las prácticas campesinas a lo largo del siglo veinte. Además, el ahorro de capital que se hace cuando se conserva un animal y el prestigio que se obtiene cuando se adquieren más de los que ya se tienen hablan de la importancia del ganado para garantizar la reproducción de los recursos y estabilizar la economía. De este modo, el ganado llevó siempre las de ganar, pues fue siempre la opción menos riesgosa.

Esta lógica cultural que propende a garantizar la reproducción de los recursos sin incurrir en demasiados riesgos se reitera en varias situaciones de la vida campesina. Tal es el caso de la adopción de los abonos químicos. Actualmente, la forma menos riesgosa de producir papa es utilizar la cantidad de agroquímicos que sean necesarios para garantizar la inversión de capital y trabajo. Esto me permite concluir que la lógica cultural campesina produce un mayor o menor impacto sobre los ecosistemas, dependiendo del tipo de práctica y del acceso que algunas familias tienen a los recursos monetarios y del entorno. Independientemente de los perjuicios ecológicos que ciertas prácticas producen, ello no quita que los campesinos(as) dejen de estar observando los cambios de los ecosistemas, formulando interpretaciones y adoptando nuevas prácticas.

De igual forma concluyo que los diferentes paisajes que se modelaron evidencian la transformación social y ambiental constante en el espacio veredal, proceso histórico que no se puede desconocer a la hora de analizar el impacto ambiental de la presencia de las familias campesinas en la alta montaña y a la hora de reservar el acceso a áreas de subpáramo y páramo. En este sentido, adhiero a los planteamientos de otros autores que consideran trascendental la integración de la "variable humana" en los estudios sobre la alta montaña (Ospina y Tocancipá, 2000). Sostengo, además, que las familias campesinas de Quebrada Honda poseen un conjunto de experiencias que puede contribuir a la recuperación de la estructura y función de los ecosistemas modificados. Son ellas y ellos quienes mejor conocen la historia de uso de las tierras de la alta montaña, la ubicación de cuerpos de agua que han desaparecido o las especies arbóreas y arbustivas que allí se encontraban. Todos estos conocimientos son fundamentales para definir estrategias de restauración de los entornos. 


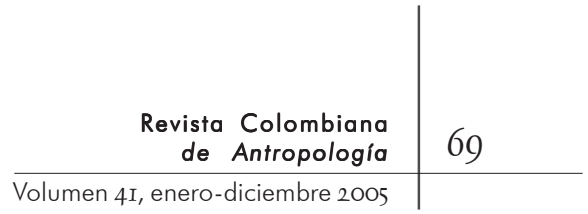

Por otro lado, la manera como las familias campesinas enfrentan las dificultades económicas producidas por la modernización agrícola da cuenta también de la vigencia de su lógica cultural. En la actualidad, ocuparse en actividades no agrícolas es una estrategia para obtener rubros complementarios que estabilizan la economía familiar. Aserrar madera, trabajar en los cultivos de flores o como aseadoras son los empleos alternativos. En un contexto mundial que se caracteriza por la "transición de una sociedad agraria organizada en torno a la actividad primaria hacia una sociedad rural más diversificada" (De Grammont, 2004: 279) en Quebrada Honda se produce la plurifuncionalidad de las unidades campesinas, sin que ello implique el abandono total de las actividades agrícolas ni la salida definitiva de los territorios rurales.

Las "unidades de producción familiar plurifuncional" se consolidan en la vereda y se convierten para muchos habitantes en el fundamento de la permanencia en la vereda. Al optar por seguir allí, las familias campesinas recurren de nuevo a su lógica cultural y se insertan en nuevos procesos de transformación de los paisajes. Con el deterioro acelerado de los recursos, las recientes políticas ambientales definen un nuevo modelo de paisaje y cuestionan el manejo que las familias campesinas le han dado a los ecosistemas de alta montaña, fundamentales para la conservación del agua. Por ello, los habitantes de la vereda han optado por organizarse para garantizar el abastecimiento del agua y el manejo colectivo del servicio en la vereda. Mujeres y hombres tienen claro que sólo de esta manera pueden garantizar su continuidad en el territorio.

Por ello concluyo que es fundamental seguir abordando las prácticas campesinas de apropiación y manejo de los recursos, para analizar la complejidad de sus formas de organización, para interpretar sus capacidades de adaptación ante los cambios y para evaluar su persistencia cultural en el espacio rural, a pesar de las transformaciones del mundo rural. Además, este trabajo deja perspectivas abiertas para otras investigaciones que busquen analizar las dinámicas de modificación de las zonas de alta montaña, mediante las cuales podamos brindar una lectura más reflexiva sobre la complejidad social y ambiental que dichos espacios integran. 


\section{ENTREVISTAS EN ORDEN DE CITACIÓN}

Juan Hernández, I3 de marzo de 2003

Fidel Páez, 22 de febrero de 2003

Gonzalo Cruz, 5 de abril de 2003

Fidelina Montaño, 23 de marzo de 2003

José Ballesteros, 8 de marzo de 2003

Manuel Rincón, I2 de febrero de 2003

Fidela Hernández, I9 de marzo de 2003.

DATOS BÁSICOS DE LOS ENTREVISTADOS

JuAN HERnÁNDEZ

Edad: 60 años.

Ocupación: pensionado de Álcalis de Colombia.

Procedencia geográfica: vereda Quebrada Honda, Cogua.

José BALlesteros

Edad: 6I años.

Ocupación: pequeño productor agropecuario.

Procedencia geográfica: San Cayetano, Cundinamarca.

Fidel PÁEz

Edad: 69 años.

Ocupación: manutención ganado lechero.

Procedencia geográfica: vereda Quebrada Honda, Cogua.

MANUEL RincóN

Edad: 72 años.

Ocupación: manutención de ovejas.

Procedencia geográfica: Tausa, Cundinamarca.

Gonzalo Cruz

Edad: 67 años.

Ocupación: pensionado de Peldar.

Procedencia geográfica: vereda Rincón Santo, Cogua. 


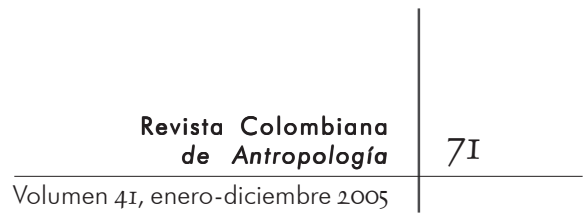

\section{MARINA DUARTE}

Edad: 60 años.

Ocupación: manutención ganado lechero.

Procedencia geográfica: vereda Quebrada Honda, Cogua.

Fidelina Montaño

Edad: 8I años.

Ocupación: manutención ganado lechero.

Procedencia geográfica: Tausa, Cundinamarca.

LEUVIGILDA ZaBALA

Edad: 75 años.

Ocupación: manutención ganado lechero.

Procedencia geográfica: vereda Quebrada Honda, Cogua.

María Delia PAChÓN

Edad: 83 años.

Ocupación: manutención ganado lechero.

Procedencia geográfica: vereda Quebrada Honda, Cogua.

María LUISA NiETO

Edad: 75 años.

Ocupación: manutención ganado lechero.

Procedencia geográfica: vereda Quebrada Honda, Cogua.

\section{Bibliografía}

Alcaldía Municipal de Cogua. I999. "Plan básico de ordenamiento territorial de Cogua. Documento resumen”. Alcaldía Municipal. Cogua.

Cano, Ingreet Juliet. 2004. "Encrucijadas de una modernización urgente: procesos de transformación social de la alta montaña y el páramo, Quebrada-Honda, Cogua-Cundinamarca”. Tesis de antropología. Universidad Nacional de Colombia, facultad de ciencias humanas. Bogotá.

Cabrera, Gustavo y Rodríguez, José. I975. "Estudio socio económico del municipio de Cogua”. Tesis de economía. Fundación Universitaria Jorge Tadeo Lozano, facultad de economía. Bogotá. 
Corporación Montaña Andina. 200i. "Conociendo mi territorio. "Expedición por Cogua”. Resumen pedagógico del ordenamiento territorial”. Comoan. Cogua.

De Grammont, Hubert. 2004. "La nueva ruralidad en América Latina”. En Revista Mexicana de Sociología. Año 66, número especial.

De Robert, Pascale. I994. "Prácticas agrícolas campesinas en el páramo de Apure, Sierra Nevada de Mérida, Venezuela”. En El uso tradicional de los recursos naturales en las montañas: tradición y transformación. Unesco. Montevideo.

Duncan, James. I989. "The power of place in Kandy, Sri Lanka: I780-I980”. John Agnew y James Duncan (eds.). The power of place. Bringind together geographical and sociological imaginations. Unwin Hyman. Londres.

Fals Borda, Orlando I979. Campesinos de los Andes. Estudio sociológico de Saucío. Punta de Lanza. Bogotá.

[1957] 1973. El hombre y la tierra en Boyacá. Desarrollo histórico de una sociedad minifundista. Punta de Lanza. Bogotá.

1959. La teoría y la realidad del cambio sociocultural en Colombia. Departamento de Sociología, Universidad Nacional de Colombia. Bogotá.

Godelier, Maurice. I989. Lo ideal y lo material. Pensamiento, economías, sociedades. Taurus Humanidades. Madrid.

GONZÁlez, JUAN MANUEL. 200I. "Una aproximación al estudio de la transformación ecológica del paisaje rural colombiano: I850-I990”. En Germán Palacio (ed.). Naturaleza en disputa: ensayos de historia ambiental en Colombia I850-1995. Universidad Nacional de Colombia. Bogotá.

GonzÁlez R., Rafael María. I973. "Desarrollo de la comunidad; síntesis de una labor I96I-I972”. Ministerio de Gobierno. Bogotá. Mimeo.

IGAC. I985. "La vegetación del páramo de la laguna verde (municipio de Tausa, Cundinarmarca)”. Análisis geográficos Igac. Bogotá.

Jimeno, Myriam, i984. "Consolidación de Estado y antropología en Colombia”. En Jaime Arocha y Nina de Friedeman. Un siglo de investigación en Colombia. Colciencias-FES. Bogotá.

Leal, Francisco y Dávila, Andrés. I99o. Clientelismo. El sistema político y su expresión regional. Tercer Mundo Editores, Instituto de Estudios Políticos y Relaciones Internacionales. Bogotá.

Molano, JOAQUín. 2002. El páramo: producción social del espacio en las altas montañas ecuatoriales. Ceso. Universidad de Los Andes. Bogotá.

Monasterio, Maximina. I980. "Poblamiento humano y uso de la tierra en los altos Andes de Venezuela”. En Maximina Monasterio (ed.). 


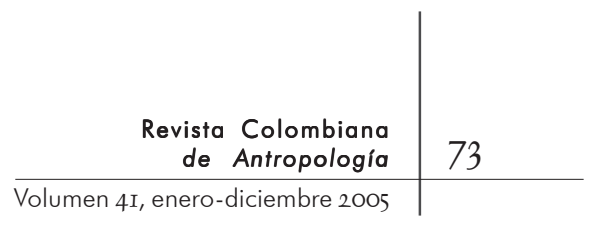

Estudios ecológicos en los páramos andinos. Universidad de los Andes. Mérida.

Ospina, Guillermo y Tocancipá, Jairo. 2000. "Los estudios sobre la alta montaña ecuatorial en Colombia". En Revista Colombiana de Antropología. 36. Enero-diciembre.

Palacio, Germán. 200I. Naturaleza en disputa: ensayos de historia ambiental en Colombia I850-I995. Universidad Nacional de Colombia. Bogotá.

Palacios, Marco. I98I. La propiedad agraria en Cundinamarca, I889I970: un esbozo sobre la sociedad de las tierras templadas. El Colegio de México. México.

Restrepo, Gabriel. I980. "El departamento de sociología de la Universidad Nacional y la tradición sociológica en Colombia”. En Sociología en Colombia. Balance y perspectivas. Memoria del III Congreso nacional de sociología.

Rivera, SERgio. I992. Neusa gooo años de presencia humana en el páramo. FIAN, Banco de la República. Bogotá.

SARMIENTO, LiNA. I994. "Elementos para la interpretación ecológica de un sistema agrícola campesino de los Andes venezolanos (páramo de Gavidia)". En El uso tradicional de los recursos naturales en las montañas: tradición y transformación. Unesco. Montevideo.

Torres, Camilo; Corredor, Berta. ig6r. Las Escuelas Radiofónicas de Sutatenza Colombia. Comisión Internacional Suiza, Departamento Socio Económico. Bogotá.

UCRÓS y MANRIQUe. I960. "Un año de experiencia en el desarrollo de una comunidad rural en Colombia 196I-I960". Acción comunal "La Plazuela" Cogua, Cundinamarca.

Vargas, Orlando y Rivera, David. I99o. "El páramo un ecosistema frágil”. En Cuadernos de Agroindustria y Economía Rural. 25.

Velandia, Roberto, 1979. Enciclopedia histórica de Cundinamarca. Tomos I y II. Biblioteca de Autores Cundinamarqueses. Bogotá.

Vera, Manuel José. I996. Cogua, nuestro bello pueblo sabanero. Cogua.

Recibido: I4 de noviembre de 2004.

Aprobado: II de septiembre de 2005. 